\title{
Kondisi arus permukaan di perairan pantai: pengamatan dengan metode Lagrangian
}

Surface current conditions in coastal waters: observations using Lagrangian method

\author{
SUDARTO $^{1}$, WILHELMINA PATTY ${ }^{1 *}$ dan ADRIE A. TARUMINGKENG ${ }^{2}$ \\ ${ }^{1}$ Program Studi Pemanfaatan Sumberdaya Perikanan, Fakultas Perikanan dan Ilmu Kelautan, \\ Universitas Sam Ratulangi, Manado 95115 \\ ${ }^{2}$ Program Studi Ilmu Kelautan, Fakultas Perikanan dan Ilmu Kelautan, Universitas Sam Ratulangi, Manado 95115
}

\begin{abstract}
Currents play an important role in providing hydrographic information, so that the measurement was performed and assessed either directly or indirectly. Lagrangian method has been used to determine the condition of the surface currents in coastal waters of Tateli Weru village. The result obtained that the tidal current was more dominant with speeds varying between $62.7 \mathrm{~cm} / \mathrm{sec}$ and $141 \mathrm{~cm} / \mathrm{sec}$ toward the east and southeast.
\end{abstract}

Keywords: currents, Lagrangian, Tateli Weru village.

\section{ABSTRAK}

Arus berperan penting dalam memberikan informasi hidrografi, sehingga pengukurannya sudah dilakukan dan dikaji baik secara langsung maupun tidak langsung. Metoda Lagrangian telah digunakan untuk mengetahui kondisi arus permukaan di perairan pantai Desa Tateli Weru. Hasil dari penelitian ini menunjukan bahwa kondisi perairan pantai di sana lebih didominasi oleh arus pasang surut dengan kecepatan bervariasi antara $62.7 \mathrm{~cm} /$ det dan $141 \mathrm{~cm} /$ det dan mengarah ke timur dan tenggara.

Kata-kata kunci: arus, Lagrangian, Desa Tateli Weru

\section{PENDAHULUAN}

Arus merupakan salah satu faktor oseanografi yang sangat menarik untuk dikaji terutama dalam menghasilkan informasi hidrografi yang bertujuan untuk kegiatan navigasi dan keselamatan pelayaran, penetapan batas wilayah atau daerah di laut, studi dinamika pesisir dan pengelolaan sumberdaya laut.

Pengukuran arus telah dilakukan sejak dahulu dengan beberapa metode baik secara langsung yaitu data kecepatan dan arah arus langsung ditampilkan oleh alat-alat pengukur arus yang

\footnotetext{
* Penulis untuk penyuratan; email:

wilhelmina.patty@yahoo.com
}

digunakan, maupun secara tidak langsung yaitu dengan memanfaatkan peranan suhu, salinitas, tekanan dan gradien potensial listrik didalam lautan (Stowe, 1987). Metode Lagrangian adalah metode pengukuran arus yang dilakukan dengan pengamatan gerakan arus permukaan dari satu titik ke titik berikutnya dalam rentang waktu tertentu (Poerbandono dan Djunasjah, 2005). Metode ini dilakukan dengan memperhitungkan jalur yang dilalui oleh setiap partikel fluida yang dinyatakan sebagai fungsi dari waktu sebagai acuan penentuan arah dan laju suatu fluida (Pickard dan Emery, 1990; Gross, 1990). Teknik ini sudah digunakan untuk mempelajari kecepatan arus di muara sungai Porong, Kabupaten Pasuruan (Warsito, 2011). Dalam studi ini metode ini telah digunakan untuk mendeskripsikan kondisi arus permukaan di perairan pantai desa Tateli Weru-Sulawesi Utara. 


\section{METODE PENELITIAN}

Alat yang dipakai untuk mengukur arus adalah Floater Current Meter (FCM) yang dihubungkan dengan GPS sebagai pencatat posisi floater. Data tersebut akan dilihat dan dicatat pada monitor GPS yang terpasang di perahu dengan kabel. Posisi awal dari alat floater ini dicatat kemudian dilepaskan ke laut dan dibiarkan terhanyut, setiap selang waktu 2 menit posisi floater ini dicatat kembali.

Pengamatan dilakukan pada tanggal 5 Juli 2013 pada empat titik lokasi pengamatan yang telah ditentukan di lokasi penelitian. Data posisi geografis (koordinat) untuk setiap titik pengukuran dicatat selama 3 kali pengulangan. Dalam selang waktu yang ditentukan, perpindahan FCM yang terjadi merupakan jarak gerak arus, dengan asumsi bahwa untuk jarak pertama yaitu perpindahan dari koordinat pertama ke koordinat kedua, sedangkan jarak kedua adalah hasil dari perpindahan koordinat kedua ke koordinat ketiga.

Kecepatan arus didapat dengan menggunakan persamaan:

$$
V=s / t
$$

dengan $V=$ kecepata arus $(\mathrm{m} / \mathrm{det}), s=$ jarak perpindahan FCM (m), $t=$ waktu (det). Untuk memperoleh data jarak perpindahan pelampung dari titik koordinat pertama $\left(Z_{1}\right)$ ke koordinat kedua $\left(Z_{2}\right)$ dan dari titik koordinat kedua $\left(Z_{2}\right)$ ke titik koordinat ke tiga $\left(Z_{3}\right)$ digunakan theorema pythagoras:

$\mathrm{Z}_{1-2}^{2}=x_{1-2}^{2}+y_{1-2}^{2}$

$\mathrm{Z}_{1-2}^{2}=\sqrt{x_{1-2}^{2}+y_{1-2}^{2}}$

$\mathrm{Z}_{2-3}^{2}=\sqrt{x_{2-3}^{2}+y_{2-3}^{2}}$
Untuk menentukan arah arus diperoleh dengan mencari sudut alpha terlebih dahulu menggunakan formula derajat dengan aplikasi rumus

$$
\alpha\left(0^{\circ}\right)=\left|\arctan \left(Z_{2-3} / Z_{1-2}\right)\right|
$$

Model mencari arah arus dapat dilihat pada Gbr. 1, dimana nilai $S$ merupakan arah arus dan variabel $\alpha$ merupakan sudut sisi miring yang dibentuk dari nilai $x$ dan nilai $y$ pada perpindahan koordinat awal $\left(Z_{1}\right)$ ke koordinat berikutnya $\left(Z_{n}\right)$. Sehingga besaran nilai $S$ adalah $+/-\alpha$.

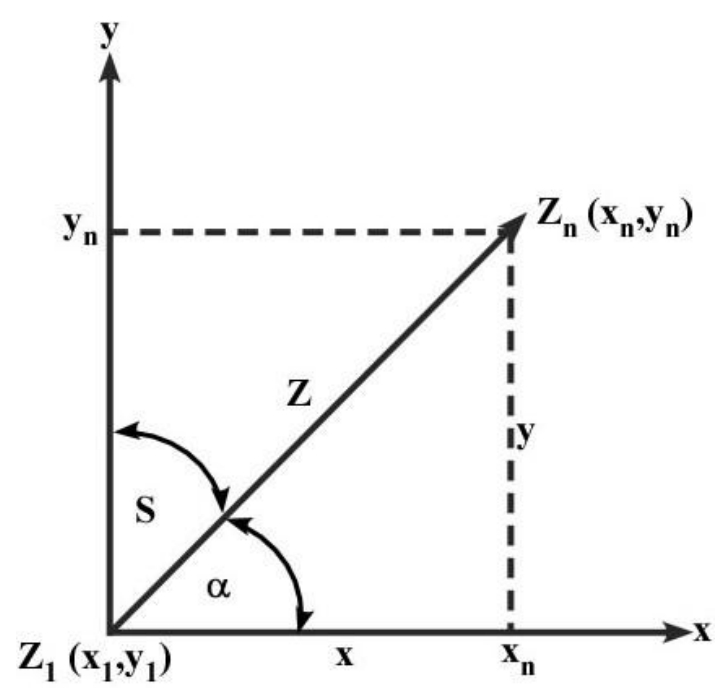

Gambar 1. Diagram model mencari arah arus

\section{HASIL}

\section{Kecepatan arus}

Data posisi ke 4 titik pengukuran dengan 3 kali pengulangan dan jarak perpindahan floater selama pengamatan dapat dilihat pada Tabel 1 dan 2 di bawah ini.

\begin{tabular}{|c|c|c|c|c|c|c|}
\hline \multirow[t]{2}{*}{$\begin{array}{c}\text { Titik } \\
\text { Pengukuran }\end{array}$} & \multicolumn{2}{|c|}{$\begin{array}{c}\text { Pengulangan-1 } \\
\left(\mathrm{Z}_{1}\right)\end{array}$} & \multicolumn{2}{|c|}{$\begin{array}{c}\text { Pengulangan-2 } \\
\left(\mathrm{Z}_{2}\right)\end{array}$} & \multicolumn{2}{|c|}{$\begin{array}{c}\text { Pengulangan-3 } \\
\left(\mathrm{Z}_{3}\right)\end{array}$} \\
\hline & $\begin{array}{c}\text { Bujur Timur } \\
\left(\mathrm{x}_{1}\right)\end{array}$ & $\begin{array}{c}\text { Lintang Utara } \\
\left(\mathrm{y}_{1}\right)\end{array}$ & $\begin{array}{c}\text { Bujur Timur } \\
\left(\mathrm{x}_{2}\right)\end{array}$ & $\begin{array}{c}\text { Lintang Utara } \\
\left(\mathrm{y}_{2}\right)\end{array}$ & $\begin{array}{c}\text { Bujur Timur } \\
\left(\mathrm{x}_{3}\right)\end{array}$ & $\begin{array}{c}\text { Lintang Utara } \\
\left(\mathrm{y}_{3}\right)\end{array}$ \\
\hline 1 & $124^{\circ} 44^{\prime} 35,7^{\prime \prime}$ & $1^{\circ} 26^{\prime} 35,5^{\prime \prime}$ & $124^{\circ} 44^{\prime} 36,6^{\prime \prime}$ & $1^{\circ} 26^{\prime} 34,6^{\prime \prime}$ & $124^{\circ} 44^{\prime} 37,2^{\prime \prime}$ & $1^{\circ} 26^{\prime} 33,6^{\prime \prime}$ \\
\hline 2 & $124^{\circ} 43^{\prime} 61,7^{\prime \prime}$ & $1^{\circ} 26^{\prime} 03,7^{\prime \prime}$ & $124^{\circ} 43^{\prime} 64,3^{\prime \prime}$ & $1^{\circ} 26^{\prime} 03,6^{\prime \prime}$ & $124^{\circ} 43^{\prime} 66,7^{\prime \prime}$ & $1^{\circ} 26^{\prime} 03,4^{\prime \prime}$ \\
\hline 3 & $124^{\circ} 44^{\prime} 03,0^{\prime \prime}$ & $1^{\circ} 27^{\prime} 08,0^{\prime \prime}$ & $124^{\circ} 44^{\prime} 05,7^{\prime \prime}$ & $1^{\circ} 27^{\prime} 08,1^{\prime \prime}$ & $124^{\circ} 44^{\prime} 08,4^{\prime \prime}$ & $1^{\circ} 27^{\prime} 07,5^{\prime \prime}$ \\
\hline 4 & $124^{\circ} 44^{\prime} 46,3^{\prime \prime}$ & $1^{\circ} 26^{\prime} 57,5^{\prime \prime}$ & $124^{\circ} 44^{\prime} 47,2^{\prime \prime}$ & $1^{\circ} 26^{\prime} 57,5^{\prime \prime}$ & $124^{\circ} 44^{\prime} 49,0^{\prime \prime}$ & $1^{\circ} 26^{\prime} 57,5^{\prime \prime}$ \\
\hline
\end{tabular}

Tabel 1. Posisi koordinat 4 titik pengukuran selam tiga kali pengulangan $\left(Z_{1}, Z_{2}\right.$, dan $\left.Z_{3}\right)$ 
Sudarto dkk.

Tabel 2. Nilai selisih jarak axis dan ordinat pada tiap titik pengukuran (m).

\begin{tabular}{ccccc}
\hline Titik Pengukuran & $\mathrm{x}_{2-1}(\mathrm{~m})$ & $\mathrm{y}_{2-1}(\mathrm{~m})$ & $\mathrm{x}_{3-2}(\mathrm{~m})$ & $\mathrm{y}_{3-2}(\mathrm{~m})$ \\
\hline 1 & 27,747 & $-27,747$ & 18,498 & $-30,83$ \\
2 & 80,158 & $-3,083$ & 73,992 & $-6,166$ \\
3 & 83,241 & 3,083 & 83,241 & $-18,498$ \\
4 & 27,747 & 0 & 55,494 & 0 \\
\hline
\end{tabular}

Tabel 3. Nilai jarak tempuh ( $\mathrm{Z}$ ) dari koordinat $\mathrm{Z}_{1-2}$ dan $\mathrm{Z}_{2-3}$

\begin{tabular}{ccc}
\hline Titik Pengukuran & $\mathrm{Z}_{1-2}(\mathrm{~m})$ & $\mathrm{Z}_{2-3}(\mathrm{~m})$ \\
\hline 1 & 39,240 & 35,954 \\
2 & 80,217 & 74,248 \\
3 & 83,298 & 85,272 \\
4 & 27,747 & 55,494 \\
\hline
\end{tabular}

Tabel 4. Nilai kecepatan arus pada empat titik pengukuran

\begin{tabular}{cccc}
\hline Titik pengukuran & $\begin{array}{c}\mathrm{Z}_{1-2} \\
(\mathrm{~m} / \mathrm{dtk})\end{array}$ & $\begin{array}{c}\mathrm{Z}_{2-3} \\
(\mathrm{~m} / \mathrm{dtk})\end{array}$ & $\begin{array}{c}\text { Resultan kecepatan arus } \\
(\mathrm{m} / \mathrm{dtk})\end{array}$ \\
\hline 1 & 0,327 & 0,300 & 0,627 \\
2 & 0,668 & 0,619 & 1,287 \\
3 & 0,694 & 0,711 & 1,405 \\
4 & 0,231 & 0,462 & 0,694 \\
\hline
\end{tabular}

Tabel 5. Hasil nilai $\alpha$

\begin{tabular}{cccc}
\hline Titik Pengukuran & A & $\alpha$ dibuat positif & $\alpha$ \\
\hline 1 & $-51,710$ & -1 & 51,710 \\
2 & $-3,434$ & -1 & 3,434 \\
3 & $-5,290$ & -1 & 5,290 \\
4 & 0 & 1 & 0 \\
\hline
\end{tabular}

Tabel 6. Hasil nilai $S$ (arah arus) yang telah dihitung.

\begin{tabular}{|c|c|c|c|c|c|c|c|c|}
\hline $\begin{array}{c}\text { Titik } \\
\text { Pengukuran }\end{array}$ & $x\left(Z_{1}\right.$ ke $\left.Z_{3}\right)$ & $\mathrm{y}\left(\mathrm{Z}_{1}\right.$ ke $\left.\mathrm{Z}_{3}\right)$ & Kuadran & $\begin{array}{c}\text { Tan } \alpha= \\
y / x\end{array}$ & $\begin{array}{c}\alpha \mathrm{x} \\
(+/-) 1\end{array}$ & $\begin{array}{c}\alpha \\
\text { dibuat } \\
\text { Positif }\end{array}$ & $\begin{array}{l}\mathrm{S}=\mathrm{SI} \\
(+/-) \alpha\end{array}$ & $\begin{array}{c}\mathrm{S}^{\mathrm{o}}\left(\mathrm{Z}_{1} \mathrm{ke}\right. \\
\left.\mathrm{Z}_{3}\right)\end{array}$ \\
\hline 1 & 513,264 & $-58,577$ & II & $-51,71$ & -1 & 51,71 & $90^{\circ}+\alpha$ & 141,71 \\
\hline 2 & 154,15 & $-9,249$ & II & $-3,434$ & -1 & 3,434 & $90^{\circ}+\alpha$ & 93,434 \\
\hline 3 & 166,482 & $-15,415$ & II & $-5,29$ & -1 & 5,29 & $90^{\circ}+\alpha$ & 95,29 \\
\hline 4 & 83,241 & 0 & -- & -_ & - & -_ & 90 & 90 \\
\hline
\end{tabular}


Jarak perpindahan floater $(Z)$ yang diperoleh dari selisih jarak axis disajikan dalam Tabel 3 . Kemudian dari jarak tersebut dihitung nilai kecepatan arus setelah dibagi dengan waktu tempuh floater yakni 2 menit (120 detik) dari tiap perpindahan $Z_{1}$ ke $Z_{2}$ dan $Z_{2}$ ke $Z_{3}$ seperti terlihat pada Tabel 4.

\section{Arah arus}

Arah arus ditentukan dengan memakai nilai axis $x$ dan $y$ yang sama dengan yang digunakan untuk menghitung kecepatan arus. Kemudian nilai ini dipakai untuk menghitung nilai $\alpha$ (Tabel 5), kemudian dari nilai ini diperoleh nilai sudut istimewa $\left(S^{0} \mathrm{Z}_{1}\right.$ ke $\left.\mathrm{Z}_{3}\right)$ yang merupakan arah arus pada 4 titik pengukuran seperti terlihat pada Tabel 6. Hasil ini menunjukkan bahwa arus permukaan yang diukur pada titik pengukuran 1 mengarah ke arah tenggara, sedangkan pada tiga titik pengukuran lainnya arus mengarah ke timur.

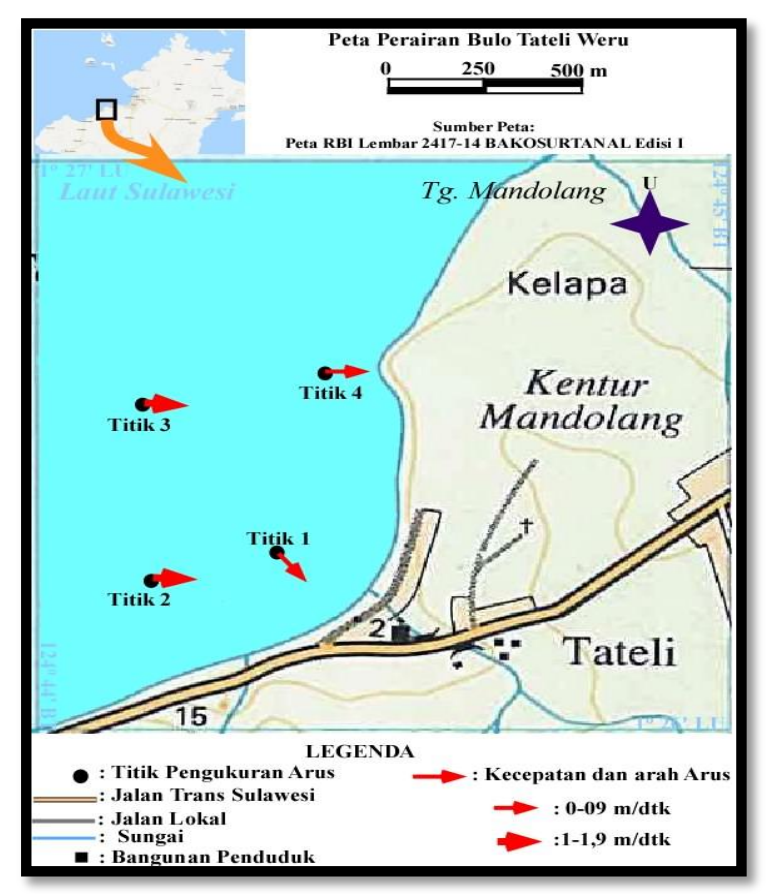

Gambar 2. Peta kecepatan dan arah arus di perairan pantai Desa Tateli-Weru

\section{PEMBAHASAN}

Hasil pengamatan ini menunjukkan bahwa kecepatan arus di perairan pantai Desa Tateli Weru yang diukur dengan metoda Lagrangian bervariasi antara $62 \mathrm{~cm} /$ det sampai $141 \mathrm{~cm} /$ det . Kecepatan arus pada posisi pengukuran dekat dengan pantai terukur lebih rendah dari pada posisi pengukuran yang ke arah laut. Hasil pengukuran kecepatan arus dengan metode yang sama di muara sungai Porong, Kabupaten Pasuruan saat bulan purnama dan perbani relatif lebih kecil yakni berkisar antara 8 sampai $27 \mathrm{~cm} /$ det (Warsito,2011). Pengaruh kedudukan geografis dan interaksi dengan perairan sekitarnya memegang peranan yang sangat penting terhadap karakteristik dinamika pantai suatu perairan (Hadikusumah, 2009).

Kondisi arus di perairan pantai pada waktu pengukuran didominasi ke arah timur dan tenggara (Gambar 2). Hal ini menunjukkan bahwa arus di perairan dibangkitkan oleh arus pasut yang saat pengamatan sedang terjadi surut.

Nilai kecepatan arus yang dihitung dengan metode Lagrangian di atas berbeda dengan nilai yang dihitung dengan metode Eulerien. Nilai kecepatan arus yang dihitung dengan menggunakan metode yang kedua relatif lebih kecil yakni berkisar antara $16.4 \mathrm{~cm} /$ det sampai $26.2 \mathrm{~cm} / \mathrm{det}$ (Tulungen dkk., 2012). Hal ini disebabkan oleh prinsip dari kecepatan arus yang diukur dengan metode Eurelien adalah pengukuran dilakukan pada satu titik tetap dengan beberapa asumsi diantaranya karakteristik aliran steady atau perilaku air yang tidak berubah dengan waktu. Hal ini berbeda dengan prinsip pengukuran dengan metode Lagrangian yang mengukur kecepatan pergerakan dalam ruang sebagai fungsi waktu dengan asumsi perilaku suatu cairan unsteady atau perilaku yang berubah dengan waktu akibat dari pengaruh angin, gelombang, dll (Ridwan, 1999).

\section{KESIMPULAN}

Kondisi arus di perairan pantai Desa Tateli Weru yang diamati dengan metode Lagrangian ternyata lebih dipengaruhi oleh arus pasang surut dengan kecepatan bervariasi antara $62 \mathrm{~cm} /$ det sampai 141 $\mathrm{cm} /$ det. Pada saat kondisi air surut arus lebih dominan mengarah ke timur dan tenggara. Untuk melengkapi informasi kondisi arus di lokasi perairan pantai ini, disarankan untuk mengamati lagi kondisi arus yang terjadi saat air pasang.

\section{DAFTAR PUSTAKA}

Gross, M.G., 1990. Oceanography. ed. $6^{\text {th }} \cdot$ Macmillan Publishing Company, New York.

Hadikusuma, 2009. Karakteristik gelombang dan arus di Eretan, Indramayu. Makara Sains 13(2): 163-172.

Pickard, G.L. dan W.J. Emery. 1990. Descriptive Physical Oceanography: An Introduction. Pergamon Press, Oxford. 
Sudarto dkk.

Poerbandono dan E. Djunasjah. 2005. Survei Hidrogafi. Refika Aditama, Bandung.

Ridwan. 1999. Mekanika Fluida Dasar. Gunadarma, Jakarta. Stowe, K. 1987. Essentials of Ocean Ccience. New York.

Tulungen, D., P.N.I. Kalangi, dan W. Patty. 2012. Kajian pola arus di daerah penangkapan bagan apung di Desa Tateli
Weru. Jurnal Ilmu dan Teknologi Perikanan Tangkap 1(2): 27-32.

Warsito, A. 2011. Studi penyebaran sedimen tersuspensi di muara sungai Porong, Kabupaten Pasuruan. Buletin Oseanografi Marina 1(2): 60-81. 